\title{
Acceptance of the 2010 George M. Kober Medal
}

\section{Stuart Kornfeld}

$\mathrm{D}$ r. Horwitz, Members of the Association, and Guests: the Kober Medal has always had a special meaning to me because of the extraordinary careers and accomplishments of the previous recipients. Consequently, it is hard to express how deeply honored I am to be selected as this year's recipient. I am also very grateful for the generous remarks of my colleague, Ajit Varki. I was aware that Ajit had been plotting with my family and friends for some time to put this presentation together, and he is a very thorough individual, so I wasn't sure what he would come up with. But I greatly enjoyed his remarks.

I am also very happy that my three children, Kathy, Carolyn, and Kerry, along with his wife, Andrea Wilson, and my dear companion, Elizabeth Loeb, are here in the audience to share this presentation.

It is the custom of the Kober Medal recipient to thank those who aided in one's career, and this is most appropriate, since mentors play such an important role in one's development. In looking back at my career, I realize how much I have benefitted from my interactions with superb mentors, colleagues, students, and postdoctorate trainees, and, at the same time, how chance has played into these events.

I first became interested in medical research as a teenager based on reading inspirational books, such as Paul De Kruif's Microbe Hunters, which describes some of the great triumphs of medicine; however, I had very little understanding of how one prepares for this type of career. In my senior year at Dartmouth College, I took a course in biochemistry, which opened my eyes to an entirely new way to understand how cells function. In that course I was exposed to the Nobel Prize-winning research of Carl and Gerty Cori on phosphorylase and glycogen

This article is adapted from a presentation at the ASCI/AAP Joint Meeting, April 23-25, 2010, in Chicago, Illinois, USA.

Address correspondence to: Stuart Kornfeld, Hematology Division, Department of Medicine, Washington University School Of Medicine, 660 S. Euclid St., Box 8125, St. Louis, Missouri 63110, USA. Phone: 314.362.8803; Fax: 314.362.8826; E-mail: skornfel@ dom.wustl.edu.

Citation for this article: JClin Invest. 2010; 120(7):2639-2640. doi:10.1172/JCI43805. metabolism performed in the Department of Biochemistry at Washington University Medical School (WUMS). This was particularly exciting to me, as I was scheduled to begin medical school at that institution in the fall. As luck would have it, my professor John Copenhaver had a good friend in the biochemistry department at WUMS, and with his help I was able to arrange an internship there for the coming summer. A few months later I found myself in the lab of a young biochemist, Luis Glaser, next door to the office of Dr. Cori. What a thrill to work and learn in that environment.

That summer I discovered a novel enzyme that converts Man-6-P to Man-1-P in baker's yeast. Little did I ever imagine that 37 years later, mutations in this enzyme would be identified as the most common cause of a new class of multisystem genetic disorders termed congenital disorders of glycosylation. It is yet another example of how basic research on simple organisms eventually makes its way into the clinic.

But the best thing that happened to me that summer is that I met a first-year biochemistry graduate student named Rosalind Hauk, who soon became my wife and scientific partner for the next 48 years.

A few years later I started my clinical rotations, and there I was exposed to an extraordinary individual, Carl V. Moore, Chairman of the Department of Medicine and a past president of the AAP. Dr. Moore was a compassionate physician beloved by his patients, a wonderful clinician and bedside teacher, and a strong proponent of the physician-scientist. He was a natural leader and set the standard for excellence. I was fortunate to obtain a position as a house officer on Dr. Moore's Ward Medicine Service, where he alternated as chief of service every six weeks with Sol Sherry, a pioneer in the field of fibrinolysis. What a marvelous experience to observe these two master clinicians discuss the pathophysiology of diseases. Dr. Moore was primarily a clinical investigator, perhaps most famous for serving as one of the subjects in the classic experiment of Bill Harrington that elucidated the etiology of idiopathic thrombocytopenic purpura as an autoimmune disorder. However, he recognized the value of training in the basic sciences as preparation for a career in biomedical research, and he encouraged his house officers to go to the NIH for research training.

With the help of Dr. Moore and Dr. Cori, I was able to secure a position at the NIH, where I had the good fortune to work in the laboratory of another young biochemist, Victor Ginsburg, one of the pioneers in the emerging field of glycobiology. There I studied the biosynthesis of blood group determinants, the only oligosaccharides with known structures at the time. I was intrigued by the fact that antibodies and plant lectins could distinguish blood group A and B, which differed by a single sugar, since this raised the possibility that specific carbohydrate structures had the potential to serve as recognition molecules in biologic processes and perhaps have roles in disease states. Vic, Rosalind, and I had many conversations on this topic, and when our two-year appointment at the $\mathrm{NIH}$ was completed, Rosalind and I decided to set out to explore this area which had received very little attention from the scientific community at the time.

We felt that WUMS would be a wonderful place to start our academic careers. So we contacted Dr. Moore and explained our desire to return to St. Louis and start a joint lab where we would study the nascent area of glycobiology, hopefully located in the Division of Hematology. Dr. Moore was receptive to this plan and after a year of residency, Rosalind and I started our joint lab.

Unbeknownst to me, at the same time, Dr. Moore hired another new faculty member for the Hematology Division from the NIH named Philip Majerus, who became my close colleague for the next 44 years. Phil is a longtime member of the AAP and delivered the Kober Lecture a number of years ago.

Dr. Moore encouraged Rosalind and me to follow our research interests even though they were quite basic at the time. We did just that, and it has been an exciting and rewarding experience to participate in the development of the field of glycobiology and to witness how advances in this area have made possible a better understanding of many aspects of normal cellular function and uncovered a number of new disease mechanisms. 
Another very rewarding aspect of being an academic physician-scientist has been the opportunity to be closely involved with the training of talented students and fellows for careers in biomedical research. Shortly after I joined the faculty in 1966, WUMS was awarded one of the initial Medical Scientist Training Program (or MSTP) grants from the NIH. This program has had an enormous impact on the medical school, especially the Department of Medicine. For the first time, medical students began to enter research labs located in clinical departments to perform their PhD thesis work. Our Hematology Division became a mixing pot, with $\mathrm{MD} / \mathrm{PhD}$ students working side by side with Hematology fellows. Soon afterwards, straight $\mathrm{PhD}$ students joined the mix. There was a lot of cross-fertilization, and the outcome has been spectacular. Twenty-six of the trainees from our division have been elected to the ASCI, and 21 to the AAP, thus far.

I have been fortunate to participate in our MSTP program since its beginning, including serving as Director for six years from 1991 to 1997. I believe that the development of the MSTP by the NIH has proven to be one of its most successful endeavors. This program has served the critical function of helping to maintain the pool of well-trained physician-scientists equipped with the skills required to apply the spectacular advances in basic science toward the understanding of disease mechanisms and the development of new therapies.

I also want to recognize the wonderful support provided by the NIH for our research. I was fortunate to be awarded an R01 grant that began the day I started my lab, and this support has continued to the present time. Those of us in the biomedical research community owe an enormous debt of gratitude to the NIH for the support it provides for our research activities.

Finally, let me close by noting that this is the centennial year of the Department of Medicine at WUMS, which was reorganized, along with other departments of the school, following the Flexner report of 1910 . Since that time, the medical school has flourished. Sixteen Nobel laureates have served on the faculty, including Herbert Gasser, who received the Kober Medal in 1944. Two former Chairmen of the Department of Medicine, W. Barry Wood, Jr., and David Kipnis, are also Kober Medalists.

In one sense, I have been associated with this school my whole life, as I was born in St. Louis Maternity Hospital, a part of the Barnes/WUMS complex. But I must confess that, growing up in St. Louis, my focus was on the St. Louis Cardinals and Stan Musial, and not on the Nobel Prize-winning research being conducted at the medical school at that time. However, WUMS has provided me with wonderful opportunities, and I'm very proud and grateful to have been associated with this institution my entire professional career.

Again, I want to thank the Association for this honor and thank my many mentors and former students and postdoctorate fellows. I only regret that my late wife and scientific partner, Rosalind Kornfeld, is not here today for this wonderful event. 